\title{
The importance of efficient territory management in distribution planning
}

\author{
Ioana Olariu, "Vasile Alecsandri” University of Bacau, Romania
}

\begin{abstract}
The current paper is a theoretical approach to the management of territories according to sales force, which has an important role in the realization of distribution. The central element is the way in which agents split their efforts between the activities and routes they are responsible with. A related issue is that of establishing what comes first - defining the sales territory or performing the selling. The effects of the interaction between the number of distribution representatives and the delimiting of the territory they cover influence the measurement of the individual elements that contribute to achieving commercial performance.
\end{abstract}

\section{Keywords}

Workload, market potential, the method of delimiting territories by accumulation, the method of delimiting territories by decomposition, time management.

\section{JEL Codes: M 31}

\section{The basic elements of territory delimitation}

Commercial territories are delimited in order to help agents sell more efficiently. Delimitation is done by allocating a number of existing and potential clients to each distribution representative (DR) acting in a given area, usually, but not always, established on geographical criteria. The reasons for territory delimitation and the criteria according to which this is done may vary a lot from one case to another. Division into commercial territories is not required or useful in all situations. Reasons against these delimitations may occur when it comes to selling to friends or social contacts, or selling with the help of references received from other existing clients, as is the case of insurance or financial investment companies. Another reason against the existence of territories could also be the small size of the market, the reduced number of clients or DR, which does not justify such a division. Where information about potential clients or concerning the way in which a product would be received is not easily available, managers should leave the demarcation of territories for when these aspects will have been clarified.

The companies establish commercial territories out of the following reasons:

- To cover the whole market. Territories allow for the identification of existing or potential clients in a given area, reducing thus the likelihood of omitting some business opportunity or the overlapping of contacts and, therefore, helping to avoid excessive transport costs.

- To define the responsibilities of each DR more accurately. This delimitation allows an easier classification of accounts by name, number and frequency of contacts.

- To better adjust the selling activity to the clients' needs. This is possible due to various reasons related to the respective location, such as knowledge of the local conditions and customs. Once more, similarity between distribution representatives and their potential clients may prove to be highly significant. 
- To improve customer relations. The distribution representatives in a given area may find out more about their clients and establish a closer relation with them, visiting them regularly, a thing which represents, by itself, a time-saving source.

But excessive contacts and wasting time with too many courtesy visits should be avoided.

- To reduce distribution expenses. The number of travels and the related costs are much more reduced if they are situated within the same area. For this reason, most of the companies insist that their distribution representatives should live in the area they cover.

- As means of facilitating performance evaluation. Commercial situations related to previous periods, to a plan or to some measure of the potential are easier to work out and more accurate when they refer to a well-defined territory. Sales managers can also draw comparisons between territories which could help them realize how to improve the activity of the entire sales personnel.

- To help the distribution representatives' work. Demarcating territories supports a better coordination among the different departments of a company, between the concrete marketing and advertising activities undertaken by it, at the same time contributing to sustaining and motivating distribution representatives who thus become managers of the areas they cover.

The most convincing reason is that territorial delimitation facilitates the implementation of the concept of marketing, contributing to a better identification of the clients' needs and allowing for more specific actions with a view to satisfying them.

In the environment in which selling and distribution take place nowadays, the ability to conduct an efficient management of territories is becoming increasingly important, this being the prerequisite for achieving optimum distribution in terms of costs.

The widely accepted procedure for establishing commercial territories covers the following five phases:

\section{Phase I: Choosing the fundamental unit}

To better define territories, one chooses a starting point that relies on different preexisting divisions, such as economic regions. The differing population density, income differences and industrial particularities make these divisions unequal in terms of their commercial potential. Where possible, it is recommended that a smaller starting unit be established, because larger commercial areas may be subsequently created by merging several of these divisions. The market features, the distribution systems and the company reputation are factors of greater influence than the simple geographical borders.

\section{Phase II: Evaluation of accounts and commercial potential}

The data systems concerning markets may provide all the information required to make decisions in this respect. In the cases where exact information may be obtained about the market and clients, territory organization can be relatively easy. This involves the classification of all potential clients into different categories, such as yet unverified tracks, existing, past or future clients. The advantages of using computerized systems materialize into the ability of quickly selecting potential accounts according to a series of relevant features. Computers can also be used in storing information about the status of the accounts, their real and potential value. The majority of companies divide their accounts according to a classification of the $\mathrm{ABC}$ type: $\mathrm{A}=$ highly important accounts, $\mathrm{B}=$ average importance accounts, $\mathrm{C}=$ less important accounts.

\section{Phase III: The analysis of distribution representatives' workload}

The agents' workload is an estimate of the time and efforts required to cover the assigned geographical territory. This approximation contains the number of accounts of different 
types, the frequency of contacts, the time allotted to each of them, the time needed to travel among contacts, as well as the time spend with non-commercial activities.

The difficulties which may arise when calculating the value of the workload include:

- Type of product. Fast-moving consumer goods require less explanations or demonstrations than technological products. The activity in this field is carried out recurrently, according to some well-established, almost routine patterns. There are, however, certain industrial or other special goods whose benefits require a more detailed presentation, making such visits take longer.

- Type of sales. Distribution representatives may deal with developing and consolidating an account which may take them more time than servicing the existing accounts. They can be faced with having to contact several persons within the same account whereas, in the other cases, they only have to meet with the actual customer. Certain types of sales require some missionary or development activity, while others may need a larger-scale promotional activity.

- The novelty of the products or of the market. In the case of developing products or markets, it is expected that there should be a need of longer time for each visit and less sales for each account than in the case of existing products or accounts. Accounts take time to develop and a large number of accounts means a greater workload in a developing area than is needed for achieving the same volume of sales in a well-established territory.

- The market share, the position and the competitive advantage of the company in the respective area. If competitors are already well positioned on the respective market, the work of distribution representatives to maintain each account will be far more difficult and will usually require more time. Most companies have a larger market share at home, that is why the task of distribution representatives is substantially more difficult when they have to work in regions away from the company's headquarters. It may happen that some agents obtain better results even in such circumstances, but this may be given rather by a greater efficiency of the distributors in the respective area than their own dealer qualities.

\section{Phase IV: Delimitation of basic territorial units}

The objective of this phase is to determine the commercial potential of the distribution representative assigned for a given area. This potential is, in its turn, related to the objectives of the sales staff. As in the case of sales forecasts, there are two distinct methods which may be used: the method of calculation by accumulation and the method of decomposition.

The procedure is as follows:

1. The number, size and location of customers are established, also taking into consideration their current, past and potential accounts. These accounts can be classified and grouped properly, for example according to size or other criteria.

2. The number of contacts needed for each account, the time and frequency of visits are determined.

3. A calculation is made concerning how many accounts each DR can serve. It is useful to use an ABC classification. Specifically, there will be an average of contacts that have to be made daily, the average frequency for each account and the average time for selling in each case.

4. The demarcation lines are drawn, taking into consideration a realistic amount of work which should be commensurate with the basic geographical unit.

The method of calculation by accumulation can be applied with the help of a computerized system. Information about each buyer resulted from the data collected during contacts may be used to maintain a file with information about clients (Vavra, 1992). Such hypotheses are more difficult to sustain in practice. Or, on the contrary, managers may adopt the method of decomposition in territory planning: starting from a nationwide estimate of the market potential and market share, one may approximate the sales potential; this estimate is then 
divided by the number of people available (or which can be recruited); finally, realistic geographical boundaries are drawn. The disadvantage of this method is that by trying to equalize the territories' commercial potential, a difference in workloads occurs which makes geographical borders unrealistic. This issue is further strengthened by the variations in market conditions and the fluctuating efficiency of distributors, so that this quite simplistic method turns out to be, in fact, quite complicated.

\section{Phase V: Assigning distribution representatives to territories}

After establishing the territories, these must be individually assigned to distribution representatives. These may differ in knowledge level, skill and ability, which makes some be more efficient than others. Practice has shown how important it is to find distribution representatives that match the customers but beside this, there are still other factors which allow them to be efficient. The managers' responsibility is to put these variables in order of priority, trying at least to improve the situation of each of them if not to find the best solution. Differences in skill, as well as the agents' desire or inclination to deal with other areas than the ones they have been assigned to may require the use of compromise which, although not optimal, is still applicable.

\section{Time management}

Most improvements in this respect may be achieved by agents themselves through more discipline and increased professionalism. Among possible improvements, we may mention:

- The work day should start earlier and end later;

- Less discussions;

- Less breaks;

- Less protocol actions.

Efficient time management means:

- Better work planning;

- Less visits to undecided or unimportant clients;

- Better use of travel and waiting time;

- An increased use of the phone, including for establishing the meeting list.

Factors which distribution representatives should take into consideration when managing their duty hours include:

- Time for elaborating official documents;

- Duration of each visit;

- Travel duration;

- Number of visits;

- Order of visits;

- Time given to developing new relations;

- Time taken by non-commercial activities;

- Time wasted in making conversations with clients.

As recommended as it might be to allow each DR to manage time on one's own, managers have the obligation not only to monitor, but also to stop the incorrect use of time and to promote more efficient practices for making sales.

\section{Conclusions}

An optimal territorial demarcation has the following features:

- areas are easy to administer;

- sales potential is relatively easy to estimate;

- time needed to travel and related costs are reduced to the minimum; 
- there is a homogeneous distribution of opportunities to sell products among existing and potential customers;

- workloads are equalized.

The most important factors to be taken into consideration when establishing territories are the market potential and the density and dispersion of accounts.

\section{References}

1. Armstrong, G.M. (1976) „The SCHEDULE model and the salesman's effort allocation”, California, Management Review, 17 (4): 43-51;

2. Cravens, D.W., Woodruff, R.B., Stamper, J.C. (1972) “An analytical approach for evaluating sales territory performance", Journal of Marketing, 36 (I): 31-37;

3. Donaldson, B. (2001) Managementul vânzărilor. Teorie şi practică, Codecs Publishing, Bucureşti;

4. Johnston, M.W., Marshall, G.W. (2006) Sales force management, McGraw-Hill Irwin Publishing, $8^{\text {th }}$ Edition, New-York;

5. Parasuraman, A., Day, R.L. (1977) "A management-oriented model for allocating sales effort", Journal of Marketing Research, XIV (Feb): 22-23;

6. Ryans, A.B., Weinberg, C.B. (1979) "Territory sales response", Journal of Marketing Research, XVI (Nov): 453-465;

7. Vavra, T.G. (1992) Aftermarketing: How to Keep Customers for Life Through Relationship Marketing, IL: Irwin, Homewood. 